\title{
Asthma and the COVID-19 pandemic: literature review
}

\author{
Mário Morais-Almeida ${ }^{1}$, Helena Pite $^{2}$, Rita Aguiar ${ }^{1}$, Ignacio J Ansotegui ${ }^{3}$, and Jean \\ Bousquet $^{4}$ \\ ${ }^{1}$ CUF-Descobertas Hospital \\ ${ }^{2}$ CUF Descobertas Hospital and CUF Infante Santo Hospital \\ ${ }^{3}$ Hospital Quironsalud Bizkaia \\ ${ }^{4}$ Université Versailles, St-Quentin-en-Yvelines
}

May 18, 2020

\begin{abstract}
Even though respiratory viruses are one of the most common triggers for asthma exacerbations, not all of these viruses affect patients equally. There is no strong evidence supporting that patients with asthma have a higher risk of becoming seriously ill from coronavirus disease 2019 (COVID-19), although recent reports from the United States of America and the United Kingdom suggest that asthma is much more common in children and adults with mild to severe COVID-19 than it was previously reported in Asia and in Europe. As in previous severe acute respiratory syndrome (SARS) outbreaks, patients with asthma, especially children, appear to be less susceptible to the coronavirus with a low rate of asthma exacerbations. Different expression of viral receptors and T2 inflammation can be responsible for different outcomes. Future studies focused on asthma and on other allergic disorders are needed to provide greater understanding of the impact of underlying asthma and allergic inflammation on COVID-19 susceptibility and disease severity. But, for the moment, it's crucial that asthmatic patients maintain their controller medication, from inhaled corticosteroids to biologics, without self-making any dose adjustments or stopping medication. New data are emerging daily, rapidly updating our understanding of this novel coronavirus.
\end{abstract}

\section{Keywords:}

Asthma, control, COVID-19, risk factors, SARS-CoV-2.

\section{Introduction}

A new coronavirus (severe acute respiratory syndrome coronavirus 2, SARS-CoV-2) infection began to disseminate in Wuhan, China in early December 2019 and has rapidly spread around the globe. The disease condition associated with this novel coronavirus is referred as coronavirus disease 2019 (COVID-19), and this outbreak was declared as a pandemic on March 11, 2020 by the World Health Organization (WHO). ${ }^{1}$ As of May 15, 2020, the outbreak had reached globally 4,580,498 confirmed cases and 305,618 deaths, and only $1,735,657$ patients recovered. ${ }^{2}$ These numbers are much greater than those registered during severe acute respiratory syndrome (SARS) and Middle East respiratory syndrome (MERS) pandemics, which occurred in 2003 and 2013, respectively, ${ }^{3}$ despite the fact that COVID-19 mortality rate, to date, is lower. ${ }^{2,3}$

SARS-CoV-2 binds mainly to angiotensin converting enzyme 2 (ACE2) receptors in host cells which are abundant in the lungs, heart, blood vessels and intestine and, after more than a decade of research, there are still no specific treatments or effective vaccines for coronavirus. ${ }^{3,4,5,6}$

COVID-19 is presenting with respiratory symptoms, from mild to severe and a significant percentage of patients develop acute respiratory disease syndrome (ARDS); these severe symptoms are associated with a true cytokine storm, in particular IL-6, and death can be one of the outcomes. ${ }^{7}$ 
Elderly and underlying morbidities, such as cardiovascular diseases, in particular hypertension and metabolic disorders (obesity and diabetes), were identified as significant risk factors for COVID-19 morbidity and mortality. ${ }^{7,8,9}$ However, asthma and COPD may not be common comorbidities. ${ }^{10}$ Moreover, the real impact of SARS-CoV-2 in asthma control is unclear.

\section{Methods}

A systematic search was carried out in 4 electronic databases: EMBASE, MEDLINE, MedRxiv, and Scopus to assess the relationship between asthma and COVID-10 using studies in English language available up to 2020 May $14^{\text {th }}$. The search terms included were "COVID-19" OR "SARS-CoV-2" OR "Coronavirus" AND "Asthma" OR "Allergy" OR "Case series" OR "Comorbidities" OR "Epidemiology" OR "Hospitalization" OR "Risk factors". Additionally, the references of the initial included studies were hand-searched to identify other possibly eligible studies.

\section{Literature review (table)}

Data from the first epidemiologic studies of the COVID-19 pandemic in China apparently did not identify asthma as a risk factor of severe COVID-19. ${ }^{10,11}$ Of 171 children treated at Wuhan Children's Hospital (Wuhan, China), three (1.8\%) required intensive care and mechanical ventilation; all of those had underlying diseases but there was no asthma reference. ${ }^{12}$ The same data was found in a cross-sectional multicenter study carried out in 10 hospitals across Hubei province (China), including hospitalized children with COVID-19. ${ }^{13}$

Dong et al (China) in a nationwide case series of 2135 pediatric patients (mean age 7 years) with COVID-19 reported to the Chinese Center for Disease Control and Prevention from January 16, 2020, to February 8,2020 (Hubei Province), did not report any asthma case. ${ }^{14}$

In a survey of 140 adult-aged admitted with COVID-19 (China), the clinical characteristics and allergy status of patients was investigated. All patients were community-acquired cases. Hypertension (30.0\%) and diabetes mellitus (12.1\%) were the most common comorbidities. Drug hypersensitivity (11.4\%) and urticaria $(1.4 \%)$ were self-reported by several patients. Asthma or other allergic diseases were not reported by any of the patients and the authors concluded that allergic diseases and asthma were not risk factors for SARS-CoV2 infection. Older age and high number of comorbidities, namely cardiovascular and metabolic diseases, were associated with COVID-19 severity. ${ }^{15}$ The same authors studied a larger sample of 290 confirmed COVID-19 adult patients hospitalized, and found only one patient with asthma $(0,3 \%)$; once again hypertension and diabetes mellitus were the most frequently found comorbidities. ${ }^{16}$

In another retrospective, multicenter cohort study that included 191 adult inpatients with confirmed COVID19 (Wuhan, China), 48\% had at least one comorbid disease, hypertension being the most common, followed by diabetes and coronary heart disease, with no asthma reference. ${ }^{17}$ In a survey of 70 adult patients admitted with COVID-19 in the Tongji Hospital (Wuhan, China), a $0.9 \%$ asthma prevalence was found, markedly lower than that in the adult population of this region (6.4\%). ${ }^{18}$ In this study, asthma was not identified as a risk factor for disease severity, in contrast with hypertension. ${ }^{18}$

A nationwide analysis from China, ${ }^{19}$ including 1,590 COVID-19 cases from 575 hospitals in 31 provincial administrative regions were collected, with an overall rate of severe cases and mortality of $16.0 \%$ and $3.2 \%$, respectively. The most prevalent comorbidity was hypertension (16.9\%), followed by diabetes (8.2\%). 130 $(8.2 \%)$ patients reported having two or more comorbidities. None of the cases had physician-diagnosed asthma. After adjusting for age and smoking status, COPD [hazards ratio (HR) 2.681, 95\% confidence interval (95\%CI) 1.424-5.048], diabetes (HR 1.59, 95\%CI 1.03-2.45), hypertension (HR 1.58, 95\% CI 1.072.32 ) and malignancy (HR 3.50, 95\% CI 1.60-7.64) were identified as significant severity risk factors, including for ICU admission, mechanical ventilation and death. ${ }^{19}$

In Europe, in a sample of 355 patients with COVID-19 who died in Italy (with a mean age of 79.5 years), it was reported that comorbidities were associated with increased mortality risk. $30 \%$ had ischemic heart disease, $35.5 \%$ had diabetes, $20.3 \%$ had active cancer, $24.5 \%$ had atrial fibrillation, $6.8 \%$ had dementia, and 
$9.6 \%$ had a history of stroke. Once again, no reference to chronic respiratory diseases was made, namely asthma or chronic obstructive pulmonary disease (COPD). ${ }^{20}$

Also in a retrospective case series of 1591 consecutive patients with laboratory-confirmed COVID-19 admitted in ICUs from 72 hospitals of the Lombardy Region, Italy, between February 20 and March 18, 2020, 68\% of patients had at least 1 comorbidity. Hypertension was the most common comorbidity, affecting $49 \%$ of 1043 patients with available data. The second most common comorbidities were cardiovascular disease $(21 \%)$ and hypercholesterolemia (18\%). Only $4 \%$ had a history of COPD, with no reference with patients with asthma. $^{21}$

In the CONFIDENCE study ${ }^{22}$ that included 100 pediatric COVID-19 cases also from Italy (median age 3,3 years), $58 \%$ with mild disease and only $1 \%$ with severe disease, there was no reference to chronic respiratory diseases as it was found in previous pediatric Chinese surveys by Lu et al ${ }^{12}$ and Dong et al. ${ }^{14}$

Barobia et $\mathrm{al}^{23}$ from La Paz University Hospital, Madrid, Spain, in a sample of 2226 adult patients (median age 61 years) admitted to the hospital who either died (20,7\%) or were discharged (79,3\%), identified that the most common comorbidity was hypertension (41.3\%), followed by other chronic cardiovascular diseases $(19,3 \%)$ and diabetes $(17,1 \%)$; asthma was identified in 5,2\% of COVID-19 patients, with a lower prevalence of $3,7 \%$ in the fatal cases. COPD affected $6,9 \%$ of the population with a prevalence of $14,1 \%$ in the fatal cases. Also from Spain, in Catalonia, Prieto-Alhambra et $\mathrm{al}^{24}$ analyzed a primary care database covering $>6$ million people, including 121,263 COVID-19 patients, both hospitalized and outpatients. Most common comorbidities were hypertension (24.3\%) and obesity (19.9\%). Asthma was present in $6,8 \%$ of the patients and COPD in $3,2 \% .10,7 \%$ of all patients were treated with inhalers.

In 200 COVID-19 patients hospitalized in the Lausanne University Hospital, Switerzland, ${ }^{25}$ an asthma prevalence of $4,0 \%$ was found, being $2,7 \%$ the asthma prevalence in those patients that required mechanical ventilation.

In the United States of America (USA), Bhatraju et $\mathrm{al}^{26}$ (Seattle) reported 24 patients with COVID-19 admitted to the intensive care unit (ICU) with a mortality rate of $50 \%$. As coexisting disorders, $58 \%$ had diabetes, $22 \%$ were current or former tobacco smokers, $21 \%$ had chronic kidney disease, and $14 \%$ had asthma, corresponding to three cases with mild asthma who had been treated with systemic corticosteroids in the week before ICU admission, as outpatients, for a presumed asthma exacerbation. These patients were subsequently admitted to the ICU with severe respiratory failure requiring invasive mechanical ventilation. ${ }^{26}$

Arentz et $\mathrm{al}^{27}$ (Washington, USA), describe in a case series the characteristics and outcomes of 21 cases of COVID-19 admitted to the ICU at Evergreen Hospital, with a mean age of 70 years-old (range 43-92 years), being the more common comorbidities identified chronic kidney disease $(47,6 \%)$, congestive heart failure $(42,9)$, diabetes $(33,3 \%)$ and COPD (33,3\%). 2 patients had asthma (9,5\%).

Data also from the USA regarding 345 cases in children ( $<18$ years) reported that $23 \%$ had at least one comorbidity. ${ }^{28}$ Chronic respiratory diseases, namely asthma, were the most common associated diseases, although the authors did not quantify the prevalence. Comorbidities were more frequently present in pediatric cases that required hospitalization compared to those that were not admitted to hospital ( $77 \%$ versus $12 \%$ ), but there was no reference of asthma as a significant risk factor. ${ }^{28}$

In a sample of 377 adult COVID-19 patients admitted in California Hospitals (USA), 7,4\% had non discriminated asthma or COPD. ${ }^{29}$ Data analysis of patients hospitalized in 14 states of the USA with COVID-19, during March $2020(\mathrm{n}=1,482),{ }^{30}$ confirmed that hospitalization was much more frequent in adults $(74.5 \%$ with [?] 50 years). Among patients with information on underlying conditions $(\mathrm{n}=120), 89 \%$ had one or more comorbidities. The most common were hypertension and other cardiovascular diseases $(77.5 \%)$, followed by obesity (48.3\%) and diabetes mellitus (28.3\%). 17,0\% of the COVID-19 positive patients had asthma and 10,7\% COPD. According the Centers for Disease Control and Prevention (CDC) report, in admitted patients aged 18-49 years, obesity was the most prevalent underlying condition (59,0\%), followed by asthma $(27,3 \%) \cdot{ }^{30}$ 
A report from eight hospitals (Georgia, USA), also summarized medical data for 305 adult patients with confirmed COVID-19 who were admitted during March 2020. Overall, 225 (73.8\%) patients had underlying conditions. Hypertension (67.5\%), diabetes (39.7\%), other cardiovascular diseases (25.6\%) and severe obesity (body mass index [?]40), which was present in $12.7 \%$ of patients. Asthma was identified in $10.5 \%$ of all patients $(13.5 \%$ in patients aged $18-49$ years-old, $13.1 \%$ in those aged $50-64$ years-old and $6.0 \%$ in those aged [?]65 years-old, with no statistically significant differences) and COPD in $5.2 \% .^{31}$

In the large sample of hospitalized COVID-patients ( $>99 \%$ adults), that included 5700 patients hospitalized with COVID-19 in the New York City Area (NY), 14.2\% were treated in the ICU, $12.2 \%$ received invasive mechanical ventilation and $21 \%$ died. ${ }^{32}$ Asthma prevalence was found in $9,0 \%$ (with no reference of asthma severity / control) and COPD in 5,4\%; most common comorbidities were hypertension (56,6\%), obesity $(41,7 \%)$ and diabetes $(33,8 \%) .{ }^{32}$

In the NY Mount Sinai Hospitals an 8,2\% prevalence of asthma was found in 2199 hospitalized patients, that was not significantly different in those that died $(7,4 \%) \cdot{ }^{33}$ Also in NY, in the first 1000 consecutive adult patients with a positive SARS-CoV-2 PCR test presented to the emergency department or were hospitalized at New York-Presbyterian/Columbia University Irving Medical Center between March 1 and April 5, 2020, an asthma prevalence of $11,3 \%$ was found, that was also not significantly different in those that were ICU admitted $(12,3 \%) \cdot{ }^{34}$

In the ISARIC Prospective Observational Cohort Study ${ }^{35}$ with near real-time analysis, with the participation of 166 United Kingdom (UK) hospitals, 16,749 COVID-19 hospitalized patients were included between 6th February and 18th April 2020, mostly adults. The commonest comorbidities were chronic cardiac disease (29\%), uncomplicated diabetes (19\%), non-asthmatic chronic pulmonary disease (19\%) and asthma (14\%); $47 \%$ had no documented reported comorbidity. Increased age and comorbidities including obesity were associated with a higher probability of mortality. ${ }^{35}$

Very recent data from the OpenSAFELY Collaborative Study, ${ }^{36}$ identified asthma as a significant risk factor of death from COVID-19 in England, United Kingdom (UK). The authors conducted a cohort study that included 17,425,445 adults using national primary care electronic health record data linked to in-hospital COVID-19 death data (from the 1st February 2020 to the 25th April 2020). Increasing age was strongly associated with risk, with the [?]80 year-age group having more than 12-fold increased risk compared with those aged 50-59 years; most comorbidities were associated with higher risk of COVID-19 hospital death, including asthma (fully adjusted hazard risk $(\mathrm{HR}) ; 95 \% \mathrm{CI}=1,11(1.02-1.20$, with a greater HR for those with recent use of an oral corticosteroid - 1,25(1,08-1.44)). ${ }^{36}$

Data from the UK Biobank, ${ }^{37}$ in a prospective case-control study, found an asthma prevalence of $17,9 \%$ in 605 COVID-19 hospitalized patients, mostly of them adults (asthma prevalence was of 13,5\% in the control population) but the disease was not identified as an independent risk factor for COVID-19 hospitalization / severity, in contrast with hypertension and COPD. In the oldest population ([?]65 year-old) included in the UK Biobank, ${ }^{38}$ the same tendency on asthma prevalence was found between patients COVID-19 hospitalized versus controls (18,2\% versus 13,0\%), but again asthma was not identified as an independent risk factor for severity.

In a report from the Middle East (Saudi Arabia) ${ }^{39}$ that included 150 hospitalized adult patients (mean age 46,1 years), it was found that $28.8 \%$ and $26.0 \%$ of the COVID-19 population had hypertension and diabetes respectively. The asthma prevalence was $2,7 \%$, and one patient with asthma was admitted in the ICU.

In a study aiming to estimate the risk factors for hospitalisation and death in the Mexican population ${ }^{40}$ infected by SARS-CoV-2 ( $\mathrm{n}=10554$, mean age 46,5 year-old, 39,4\% hospitalized and 9,2\% fatal cases), hypertension was the most prevalent comorbidity found (21.7\%), followed by obesity $(20.15 \%)$ and diabetes $(17.7 \%)$. Asthma prevalence was $3,6 \%$ of this population $(3,1 \%$ in the hospitalized patients and in $3,2 \%$ in the fatal cases). Patients with hypertension, obesity, and diabetes were more likely to be hospitalised and die than people without these comorbidities. Once again asthma was not identified as an independent risk factor for hospitalization and/or mortality. ${ }^{40}$ 


\section{Discussion}

Based on the available literature, there was no clear evidence that patients with asthma were at a higher risk of being infected or becoming severely ill with SARS-CoV-2, although recent reports from the USA and the UK suggest that asthma is much more common in children and adults with COVID-19 than it was previously reported in Asia and in the first surveys in continental Europe.

Nevertheless, the prevalence of several underlying conditions identified in USA hospitalized patients with COVID-19 were similar to those for hospitalized influenza patients during influenza seasons 2014-15 through 2018-19, namely regarding chronic respiratory diseases (29\% to $31 \%){ }^{41}$

Of particular note in the UK results of the association of asthma with higher risk of COVID-19 hospital death, with the HR increasing further for those that received oral corticosteroid (OCS), probably indicating greater severity of disease. This contrasts with previous findings, in several countries, where asthma and other chronic respiratory diseases were underrepresented in hospitalized patients. ${ }^{36}$ Also in the UK it was reported asthma in 14,0\% and 17,9\% of hospitalized patients but with no increased risk of death. ${ }^{35,37}$

Among school-age children, viral infection reportedly accounts for up to $85 \%$ of asthma exacerbations, and viruses are more frequently isolated from symptomatic patients than from asymptomatic patients. ${ }^{42,43}$ Even though respiratory viruses are one of the most common triggers for asthma exacerbations in all age groups, not all of these viruses affect patients equally. In particular, the human rhinovirus was identified as the main individual contributor for asthma exacerbations, being coronavirus one of the less identified trigger of asthma exacerbations in children as in adults. ${ }^{44} \mathrm{~A}$ recent literature review concerning virus detection during asthma exacerbations, confirmed that exacerbations were mainly associated with rhinovirus infection in all continents. ${ }^{45}$

In previous SARS outbreaks, patients with asthma, in particular children, appeared to be less susceptible to the coronavirus, with reported low rate of asthma exacerbations and good prognosis on follow-up. ${ }^{10,46} \mathrm{In}$ contrast, during influenza epidemics, asthma was associated with more severe disease, including the need of mechanical ventilation, not only in adults but also in children. ${ }^{47}$ The exact reasons for this remain unknown, but it was confirmed during the current coronavirus pandemic. ${ }^{48}$

From the recent COVID-19 literature, no definite conclusions can be drawn regarding asthma control or severity. Similarly, no information can be extrapolated about asthma phenotypes, namely regarding whether asthma was allergic or not.

COVID-19 outcomes vary from asymptomatic infection to death and it is possible that this clinical range may reflect different airway levels of the SARS-CoV-2 receptor, ACE2, and the spike protein activator transmembrane protease serine 2 (TMPRSS2), considering that the virus cell entry also depends on S-protein priming by host cell proteases.

Blood eosinophil levels are a well-known predictor of airway T2 inflammation, ${ }^{49}$ and the measurement of blood eosinophil levels can be used as an accessible (not strong), proxy for investigating the association between airway T2 inflammation and COVID-19 outcomes.

In early reports from China, a detailed clinical investigation of hospitalized COVID-19 cases suggested severe eosinopenia together with lymphopenia as a potential indicator for diagnosis and to a worse prognosis, including death. ${ }^{15}$ It was believed that low eosinophil counts in peripheral blood would be related with the SARS-CoV-2 infection itself. However, more recent studies from China and from Italy did not report eosinopenia in patients with severe COVID-19. ${ }^{26,31,50}$

Although the relationship between eosinophil counts and COVID-19 is uncertain, attention is warranted to monitor eosinophil counts among patients with asthma who are using biological therapies that lead to decreased eosinophil counts, and the clinical course of COVID-19 if they get infected with the SARS-CoV-2. ${ }^{51}$

Sajuthi et $\mathrm{al}^{52}$ studied in children the role for both $\mathrm{T} 2$ inflammation and viral infection in regulating the gene expression of ACE2 and TMPRSS2 and found a strong influence of T2 cytokine-driven inflammation 
on both ACE2 (downregulation) and TMPRSS2 (upregulation) expression levels, which can have clinical implications on COVID-19 outcomes. In contrast, the authors found an equally strong positive influence of respiratory virus infections on ACE2 expression. ${ }^{52}$ So, at least theoretically, in patients with asthma and high T2 inflammation, the consequence of an interferon dependent inflammation requires a close monitoring given the enhanced risk of complications due to SARS-CoV-2 infection.

A recent study that included asthma patients from three different cohorts of children and adults, found that ACE2 receptors expression was lower in those patients with high allergic sensitization, but non-atopic asthma was not associated with this reduced expression. ${ }^{53}$ These data suggest that this reduced ACE2 expression may be a potential contributor, among several other factors, of reduced COVID-19 severity in patients with respiratory allergies, namely allergic asthma. ${ }^{53}$

Additionally, there is some early evidence coming from the Severe Asthma Research Program-3 (SARP), that inhaled corticosteroid therapy is also associated with reduction on ACE2 and TMPRSS2 gene expression from sputum. ${ }^{54}$ These data stress the importance of maintain asthma controlled using the treatment according to the best practices, including with inhaled steroids.

There is also evidence to support that taking ICS may be beneficial in dealing with coronavirus infections. In vitro studies showed inhibitory actions of budesonide on coronavirus $\mathrm{HCoV}-229 \mathrm{E}$ replication and cytokine production $^{55}$ and, preliminary not yet peer-reviewed data, suggest that ciclesonide blocks SARS-CoV-2 ribonucleic acid replication ${ }^{56}$ and inhibits its cytopathic activity ${ }^{57}$ which may have clinical implications.

Although gene expression for ACE2 and TMPRSS2 did not differ in healthy and asthmatic patients, it was also found that males, African Americans and patients with diabetes have increased expression of ACE2 and TMPRSS2 in their sputum cells, which may be associated with the poor prognosis of these patients when infected with the SARS-CoV-2. ${ }^{54}$

Dong et al. ${ }^{58}$ very elegantly described selected cases of patients with COVID-19, children and adults, demonstrating the profile complexity and different clinical presentations from mild to severe cases. Patients with common allergic diseases, such as rhinitis or atopic dermatitis, did not develop distinct symptoms or had severe courses, which may suggest a positive balance of type 2 immune regulation in COVID-19 pathogenesis.

New data are emerging daily, rapidly updating our understanding of this novel coronavirus, but it's crucial that patients with asthma and other allergic diseases such as allergic rhinitis, maintain their controller medication, from inhaled corticosteroids to biologics, ${ }^{51,59,60}$ including allergen immunotherapy, ${ }^{61}$ without self-making any dose adjustments or stopping medication that may lead to higher risk of asthma exacerbations, increased OCS use and higher probability to emergency room access and hospitalization that represent themselves risk factors for coronavirus exposure and spread. Likewise, it is important to maintain well-controlled rhinitis and rhinosinusitis, together with other known risk factors for asthma exacerbations. ${ }^{62}$

The available data about OCS use in asthma exacerbations, although limited to 3 reported cases in mild asthmatics, ${ }^{26}$ are in accordance with data from previous coronavirus outbreaks, showing that systemic corticosteroids can be associated with a higher viral load. ${ }^{63,64}$ The UK data suggesting an increased death risk in patients with asthma specially in those that recently received systemic steroids, ${ }^{36}$ stress that clinicians must be cautious and recognize the differences between hypoxic respiratory failure and bronchospasm to carefully balance the need for OCS prescription, ${ }^{51}$ and bronchodilators must be delivered by metered dose inhalers with spacers in order to prevent the viral spread related with nebulizers use. ${ }^{65}$

As it was shown by Kaye et al, ${ }^{66}$ there is evidence on increased adherence to asthma (and COPD) pharmacologic treatment during the first months of the COVID-19 which is encouraging, and hopefully will have a positive effect on improving control of asthma and minimize the need for acute care for this inflammatory chronic respiratory disease.

In conclusion, it is unclear whether patients with asthma are at higher of developing COVID-19 and/or become severely ill. Future studies in all age groups are needed to provide greater understanding of the impact of underlying asthma, other allergic diseases and T2 inflammation on COVID-19 susceptibility and 
disease outcomes. The best we will understand these interactions, the best we will protect the most vulnerable people included in high risk groups.

Table: Asthma prevalence in COVID-19 studies

\begin{tabular}{lll}
\hline Study & Ref & Country \\
\hline Children's Hospital, Wuhan & 12 & China \\
Hubei province & 13 & China \\
Nationwide China & 14 & China \\
Zhongnan Hospital of Wuhan & 15 & China \\
Zhongnan Hospital of Wuhan & 16 & China \\
Multicentric study, Wuhan & 17 & China \\
Tongji Hospital of Wuhan & 18 & China \\
Nationwide China & 19 & China \\
19 Italian regions and 2 autonomous provinces & 20 & Italy \\
Lombardy region & 21 & Italy \\
Confidence study & 22 & Italy \\
La Paz Hospital & 23 & Spain \\
Catalonia Region & 24 & Spain \\
Lausanne University Hospital & 25 & Switzerland \\
Seattle Region & 26 & USA \\
Evergreen Hospital, Washington & 27 & USA \\
COVID-19 in Children & 28 & USA \\
Kaiser Permanente Northern California & 29 & USA \\
COVID-NET, 14 states & 30 & USA \\
Georgia, 8 hospitals & 31 & USA \\
New York City Area & 32 & USA \\
Mount Sinai Hospitals, New York & 33 & USA \\
ISARIC study & 34 & USA \\
OpenSAFELY case control populational study & 35 & UK \\
UK BioBank & 36 & UK
\end{tabular}

Legend: HR - hazard risk; ICU - Intensive Care Unit; OCS - oral corticosteroids; USA - United States of America; UK - United Kingdom

\section{References}

1.https://www.who.int/dg/speeches/detail/who-director-general-s-opening-remarks-at-the-media-briefing-oncovid-19-11-march-2020(Accessed 27-Mar-2020).

2. https://www.worldometers.info/coronavirus/ (Accessed 15-May-2020).

3. Wang Y, Wang Y, Chen Y, Qin Q. Unique epidemiological and clinical features of the emerging 2019 novel coronavirus pneumonia (COVID-19) implicate special control measures. J Med Virol. 2020 Mar 5. doi: $10.1002 / \mathrm{jmv} .25748$.

4. Wu F, Zhao S, Yu B, et al. A new coronavirus associated with human respiratory disease in China. Nature. 2020;579(7798):265-269.

5. Abassi ZA, Skorecki K, Heyman SN, Kinaneh S, Armaly Z. Covid-19 infection and mortality - A physiologist's perspective enlightening clinical features and plausible interventional strategies. Am J Physiol Lung 
Cell Mol Physiol. 2020 Mar 24.doi:10.1152/ajplung.00097.2020.

6. Sanders JM, Monogue ML, Jodlowski TZ, Cutrell JB. Pharmacologic treatments for Coronavirus Disease 2019 (COVID-19): A Review. JAMA. 2020 Apr 13. doi: 10.1001/jama.2020.6019.

7. Lupia T, Scabini S, Mornese Pinna S, Di Perri G, De Rosa FG, Corcione S. 2019 novel coronavirus (2019-nCoV) outbreak: A new challenge. J Glob Antimicrob Resist. 2020;21:22-27.

8. Yang J, Zheng Y, Gou X, et al. Prevalence of comorbidities and its effects in coronavirus disease 2019 patients: A systematic review and meta-analysis. Int J Infect Dis. 2020;94:91-95.

9. Fang L, Karakiulakis G, Roth M. Are patients with hypertension and diabetes mellitus at increased risk for COVID-19 infection? Lancet Respir Med. 2020 Mar 11. pii: S2213-2600(20)30116-8. doi: 10.1016/S22132600(20)30116-8.

10. Halpin D, Faner R, Sibila O, Badia J, Agusti A. Do chronic respiratory diseases or their treatment affect the risk of SARS-CoV-2 infection? Lancet Respir Med 2020 April 3, 2020.https://doi.org/10.1016/S22132600(20)30167-3.

11. Wu Z, McGoogan JM. Characteristics of and important lessons from the Coronavirus Disease 2019 (COVID-19) outbreak in China - Summary of a report of 72314 cases from the chinese Center for Disease Control and Prevention. JAMA. 2020;323(13):1239-1242.

12. Lu X, Zhang L, Du H, et al; Chinese Pediatric Novel Coronavirus Study Team. SARS-CoV-2 infection in children. N Engl J Med. 2020 Mar 18. doi: 10.1056/NEJMc2005073.

13. Zheng F, Liao C, Fan QH, et al. Clinical characteristics of children with Coronavirus Disease 2019 in Hubei, China. Curr Med Sci. 2020;40(2):275-280.

14. Dong Y, Mo X, Hu Y, et al. Epidemiology of COVID-19 among children in China. Pediatrics. 2020;145(6):e20200702.

15. Zhang JJ, Dong X, Cao YY, et al. Clinical characteristics of 140 patients infected with SARS-CoV-2 in Wuhan, China. Allergy. 2020 Feb 19. doi: 10.1111/all.14238.

16. Zhang JJ, Cao Y, Dong X, et al. Distinct characteristics of COVID-19 patients with initial rRT-PCRpositive and rRT-PCR-negative results for SARS-CoV-2. Allergy. 2020. DOI: 10.1111/all.14316.

17. Zhou F, Yu T, Du R, et al. Clinical course and risk factors for mortality of adult inpatients with COVID19 in Wuhan, China: a retrospective cohort study. Lancet. 2020 Mar 11. pii: S0140-6736(20)30566-3. doi: 10.1016/S0140-6736(20)30566-3.

18. Li X, Xu S, Yu M, et al. Risk factors for severity and mortality in adult COVID-19 inpatients in Wuhan. J Allergy Clin Immunol. 2020 Apr 12. pii: S0091-6749(20)30495-4. doi: 10.1016/j.jaci.2020.04.006.

19. Guan WJ, Liang WH, Zhao Y, et al; China Medical Treatment Expert Group for Covid-19. Comorbidity and its impact on 1590 patients with Covid-19 in China: A nationwide analysis. Eur Respir J. 2020 Mar 26. pii: 2000547. doi: 10.1183/13993003.00547-2020.

20. Onder G, Rezza G, Brusaferro S. Case-fatality rate and characteristics of patients dying in relation to COVID-19 in Italy. JAMA. 2020 Mar 23. doi: 10.1001/jama.2020.4683.

21. Grasselli G, Zangrillo A, Zanella A, Antonelli M, Cabrini L, Castelli A. Baseline characteristics and outcomes of 1591 patients infected with SARS-CoV-2 admitted to ICUs of the Lombardy Region, Italy. JAMA. 2020 Apr 6. doi: 10.1001/jama.2020.5394.

22. Niccolò Parri, Matteo Lenge, Danilo Buonsenso, for the Coronavirus Infection in Pediatric Emergency Departments (CONFIDENCE) Research Group. Children with Covid-19 in pediatric emergency departments in Italy. N Engl J Med. 2020. DOI: 10.1056/NEJMc2007617. 
23. Borobia AM, Carcas AJ, Arnalich F, et al; for the COVID@HULP Working Group. A cohort of patients with COVID-19 in a major teaching hospital in Europe. 2000 May 6. medRxiv preprint doi:https://doi.org/10.1101/2020.04.29.20080853.

24. Prieto-Alhambra D, Balló E, Coma E, et al. Hospitalization and 30-day fatality in 121,263 COVID-19 outpatient cases. 2020 May 8. medRxiv preprint doi:https://doi.org/10.1101/2020.05.04.20090050.

25. Regina J, Papadimitriou-Olivgeris M, Burger R, Filippidis P, Tschopp J, Desgranges F. Epidemiology, risk factors and clinical course of SARS-CoV-2 infected patients in a Swiss university hospital: an observational retrospective study. 2020 May 14. medRxiv preprint doi:https://doi.org/10.1101/2020.05.11.20097741.

26. Bhatraju PK, Ghassemieh BJ, Nichols M, et al. Covid-19 in critically ill patients in the Seattle Region — Case series. N Engl J Med. 2020; DOI: 10.1056/NEJMoa2004500.doi.

27. Arentz M, Yim E, Klaff L, et al. Characteristics and outcomes of 21 critically ill patients with COVID-19 in Washington State. JAMA. 2020 Mar 19. doi: 10.1001/jama.2020.4326. [Epub ahead of print]

28. CDC COVID-19 Response Team. Coronavirus Disease 2019 in Children - United States, February 12April 2, 2020. MMWR Morb Mortal Wkly Rep. 2020;69(14):422-426.

29. Myers LC, Parodi SM, Escobar GJ, Liu VX. Characteristics of hospitalized adults with COVID-19 in an integrated health care system in California. JAMA. 2020 Apr 24. doi: 10.1001/jama.2020.7202.

30. Garg S, Kim L, Whitaker M, et al. Hospitalization rates and characteristics of patients hospitalized with laboratory-confirmed Coronavirus Disease 2019 - COVID-NET, 14 States, March 1-30, 2020. MMWR Morb Mortal Wkly Rep. 2020;69(15):458-464.

31. Gold JAW, Wong KK, Szablewski CM, et al. Characteristics and clinical outcomes of adult patients hospitalized with COVID-19 - Georgia, March 2020. MMWR. 2020;69(18):545-550.

32. Richardson S, Hirsch JS, Narasimhan M, et al; the Northwell COVID-19 Research Consortium. Presenting characteristics, comorbidities, and outcomes among 5700 patients hospitalized with COVID-19 in the NewYork City area. JAMA. 2020. doi:10.1001/jama.2020.6775.

33. Paranjpe I, Russak AJ, De Freitas JK, Lala A, Miotto R, Vaid A. Clinical characteristics of hospitalized Covid-19 patients in New York City. 2020 April 26. medRxiv preprint doi: https://doi.org/10.1101/2020.04.19.20062117.

34. Argenziano MG, Bruce SL, Slater CL, Tiao JR, Baldwin MR, Hamilton GR, et al. Characterization and clinical course of 1000 patients with COVID-19 in New York: retrospective case series. 2020 May 7. medRxiv preprint doi: https://doi.org/10.1101/2020.04.20.20072116.

35. Docherty AB, Harrison EM, Green CA, et al. Features of 16,749 hospitalised UK patients with COVID-19 using the ISARIC WHO clinical characterisation protocol. medRxiv (2020) doi:10.1101/2020.04.23.20076042.

36. Williamson E, Walker AJ, Bhaskaran K, Bacon S, Bates C, Morton CE; The OpenSAFELY Collaborative. OpenSAFELY: factors associated with COVID-19-related hospital death in the linked electronic health records of 17 million adult NHS patients. 2020 May 7. doi: https://doi.org/10.1101/2020.05.06.20092999. medRxiv preprint.

37. Khawaja AP, Warwick AN, Hysi PG, et al. Associations with covid-19 hospitalisation amongst 406,793 adults: the UK Biobank prospective cohort study. 2020 May 11. medRxiv preprint doi: https://doi.org/10.1101/2020.05.06.20092957.

38. Atkins JL, Masoli JÁ, Delgado J, et al. Preexisting comorbidities predicting severe COVID-19 in older adults in the UK Biobank community cohort. 2020 May 8. medRxiv preprint doi: https://doi.org/10.1101/2020.05.06.20092700. 
39. Shabrawishi M, Al-Gethamy MM, Naser AY, et al. Clinical, Radiological and therapeutic characteristics of patients with COVID-19 in Saudi Arabia. 2020 May 12. edRxiv preprint doi: https://doi.org/10.1101/2020.05.07.20094169.

40. Carrillo-Veja MF, Salinas-Escudero G, García-Peña C, Gutiérrez-Robledo LM, Parra-Rodríguez L. Early estimation of the risk factors for hospitalisation and mortality by COVID-19 in México. 2020 May 14. medRxiv preprint doi: https://doi.org/10.1101/2020.05.11.20098145.

41. FluView interactive: laboratory-confirmed influenza hospitalizations. Atlanta, GA: US Department of Health and Human Services, CDC; 2020. https://www.cdc.gov/flu/weekly/ fluviewinteractive.htm ref (Accessed 24-April-2020).

42. Johnston SL, Pattemore PK, Sanderson G, et al. Community study of role of viral infections in exacerbations of asthma in 9-11 year old children. BMJ. 1995;310:1225-1229.

43. Papadopoulos NG, Christodoulou I, Rohde G, et al. Viruses and bacteria in acute asthma exacerbationsa GA2LEN-DARE systematic review. Allergy. 2011;66:458-468.

44. Satia I, Cusack R, Greene JM, O'Byrne PM, Killian KJ, Johnston N. Prevalence and contribution of respiratory viruses in the community to rates of emergency department visits and hospitalizations with respiratory tract infections, chronic obstructive pulmonary disease and asthma. PLoS One. 2020;15(2):e0228544.

45. Zheng X-Y, Xu Y-J, Guan W-J, Lin L-F. Regional, age and respiratory-secretion-specific prevalence of respiratory viruses associated with asthma exacerbation: a literature review. Arch Virol. 2018;163(4):845-853.

46. van Bever HP, Chng SY, Goh DY. Childhood severe acute respiratory syndrome, coronavirus infections and asthma. Pediatr Allergy Immunol. 2004;15(3):206-209.

47. Tokuhira N, Shime N, Inoue M, et al, Writing Committee of AH1N1 Investigators; Japanese Society of Intensive Care Medicine Pediatric Intensive Care Unit Network. Mechanically ventilated children with 2009 pandemic Influenza A/H1N1: results from the national pediatric intensive care registry in Japan. Pediatr Crit Care Med. 2012;13(5):294-298.

48. Ludvigsson JF. Systematic review of COVID-19 in children show milder cases and a better prognosis than adults. Acta Paediatr. 2020 Mar 23. doi: 0.1111/apa.15270.

49. Woodruff PG, Modrek B, Choy DF, et al. T-helper Type 2-driven inflammation defines major subphenotypes of asthma. Am J Resp Crit Care Med. 2009;180:388-395.

50. Zhu J, Ji P, Pang J, et al. Clinical characteristics of 3,062 COVID-19 patients: a meta-analysis. J Med Virol. 2020 Apr 15. doi: 10.1002/jmv.25884.

51. Morais-Almeida M, Aguiar R, Martin B, et al. COVID-19, asthma and biologic therapies: what we need to know. World Allergy Organ J. 2020 (in press ).

52. Sajuthi SP, DeFord P, Jackson ND, et al. Type 2 and interferon inflammation strongly regulate SARSCoV-2 related gene expression in the airway epithelium. bioRxiv 2020.2020.04.09.034454.

53. Jackson DJ, Busse WW, Bacharier LB, et al. Association of respiratory allergy, asthma and expression of the SARS-CoV-2 receptor, ACE2. J Allergy Clin Immunol. 2020, doi: https://doi.org/10.1016/j.jaci.200.04.009.

54. Peters MC, Sajuthi S, Deford P, et al. SARS-COV-2 Related Genes in Sputum Cells in Asthma: Relationship to Demographic Features and Corticosteroids. Am J Respir Crit Care Med. 2020 Apr 29. doi: 10.1164/rccm.202003-0821OC.

55. Yamaya M, Nishimura H, Deng X, et al. Inhibitory effects of glycopyrronium, formoterol, and budesonide on coronavirus $\mathrm{HCoV}-229 \mathrm{E}$ replication and cytokine production by primary cultures of human nasal and tracheal epithelial cells. Respir Investig. 2020. Epub 2020/02/26. 
56. Matsuyama S, Kawase M, Nao N, et al. The inhaled corticosteroid ciclesonide blocks coronavirus RNA replication by targeting viral NSP15. bioRxiv. 2020:2020.03.11.987016.

57. Jeon S, Ko M, Lee J, et al. Identification of antiviral drug candidates against SARS-CoV-2 from FDAapproved drugs. bioRxiv. 2020:2020.03.20.999730.

58. Dong X, Cao YY, Lu XX, et al. Eleven faces of coronavirus disease 2019. Allergy. 2020 Mar 20. doi: 10.1111/all.14289.

59. Global Initiative for Asthma. 2020 GINA Report, Global Strategy for Asthma Management and Prevention 2020. Available from:www.ginasthma.org (Accessed 28-Apr-2020).

60. Halpin DMG, Singh D, Hadfield RM. Inhaled corticosteroids and COVID-19: a systematic review and clinical perspective. Eur Respir J. 2020 Apr 27. pii: 2001009. doi: 10.1183/13993003.01009-2020.

61. Klimek L, Jutel M, Akdis C, at al. Handling of allergen immunotherapy in the COVID-19 pandemic: An ARIA-EAACI statement. Klimek L, Jutel M, Akdis C, at al. Allergy. 2020 Apr 24. doi: 10.1111/all.14336.

62. Bousquet J, Akdis C, Jutel M, et al; ARIA-MASK study group. Intranasal corticosteroids in allergic rhinitis in COVID-19 infected patients: An ARIA-EAACI statement. Allergy. 2020 Mar 31. doi: 10.1111/all.14302.

63. Lee N, Allen Chan KC, Hui DS, et al. Effects of early corticosteroid treatment on plasma SARS-associated Coronavirus RNA concentrations in adult patients. J Clin Virol. 2004;31(4):304-309.

64. Arabi YM, Mandourah Y, Al-Hameed F, et al; Saudi Critical Care Trial Group. Corticosteroid therapy for critically ill patients with Middle East Respiratory Syndrome. Am J Respir Crit Care Med. 2018;197(6):757767.

65. Levin M, Morais-Almeida M, Ansotegui I, et al. Acute asthma management during SARS-CoV2-pandemic 2020. World Allergy Organ J. 2020 May 14:100125. doi: 10.1016/j.waojou.2020.100125.

66. Kaye L, Theye B, Smeenk I, Gondalia R, Barrett MA, Stempel DA. J Alllergy Clin Immunol Practice. 2020. https://doi.org/10.1016/j.jaip.2020.04.053. 